Johnson \& Wales University ScholarsArchive@JWU

Engineering Studies Faculty Publications and

Creative Works

College of Engineering \& Design

$11-9-1996$

\title{
Arts, Computers and Artificial Intelligence
}

Sol Neeman Ph.D.

Johnson \& Wales University - Providence, sneeman@jwu.edu

Follow this and additional works at: https://scholarsarchive.jwu.edu/engineering_fac

Part of the Computer Engineering Commons, Electrical and Computer Engineering Commons, Engineering Science and Materials Commons, Mechanical Engineering Commons, Operations Research, Systems Engineering and Industrial Engineering Commons, and the Other Engineering Commons

\section{Repository Citation}

Neeman, Sol Ph.D., "Arts, Computers and Artificial Intelligence" (1996). Engineering Studies Faculty Publications and Creative Works. 4. https://scholarsarchive.jwu.edu/engineering_fac/4

This Conference Proceeding is brought to you for free and open access by the College of Engineering \& Design at ScholarsArchive@JWU. It has been accepted for inclusion in Engineering Studies Faculty Publications and Creative Works by an authorized administrator of ScholarsArchive@JWU. For more information, please contact jcastel@jwu.edu. 


\title{
Arts, Computers and Artificial Intelligence
}

\author{
Sol Neeman \\ School of Technology \\ Johnson and Wales University \\ Providence, RI 02903
}

\begin{abstract}
Science and art seem to belong to different cultures. Science and technology, mainly the products of the intellect, use terminology and vocabulary that are concise and well defined. In contrast, in artistic expression, ambiguity is a powerful component. Still the relationship between these two different categories of human activity is interesting and fascinating.

In this paper, a general comparison of these two disciplines will be introduced. Then the possibility of mechanical creation of art using computers and artificial intelligence will be discussed. This will be followed by two techniques which are used to create poetry and music. First, a statistical approach for mechanical composition of music will be presented. This method uses "parameters" of existing music to create "similar" music. Second, a method of mechanical composition of poetry will be presented which combines linguistic models, a classification dictionary and semantic information.
\end{abstract}

\section{Introduction}

It is probably easier to come up with arguments differentiating the disciplines of art and science than to find characteristics common to both. Still, trying to combine both seems to be an interesting challenge which has the potential to produce some exciting results.

As computers and artificial intelligence are important components of technology, and the latter is a derivative of science, it would be worthwhile to observe some of the important differences between science and art:

\section{Intellect/Emotions}

Science is a pure product of the intellect. Art, on the other hand, involves the intellect, emotions and feelings, both in its creation and appreciation.

\section{Well defined discipline/ Cannot be defined}

Science and technology are based on concepts and terminology which are well defined and concise. Computer output is a function of the program and the data and, in this respect, its behavior is deterministic and predictable. On the other hand, one does not want art to be completely predictable. Hidden ambiguity in a mathematical problem can lead to contradiction and paradox. In art, it is used as a tool to enrich and increase curiosity and aesthetic tension. "What is art?", is a question which has many answers. The essence of art, what makes a piece of art valuable, cannot be defined and cannot be presented in any formal description (e.g. through an equation or an algorithm). In other words, the artistic value is encrypted in such a way that it would be difficult if not impossible to decipher.

\section{Quantitative/Qualitative}

Science and technology describe the physical world in quantitative terms. For example, to solve any problem on a computer one has to quantify it. Even in cases where individual events within a group cannot be presented in deterministic form, science has found a tool to provide quantitative description using probability and frequency distribution. In art, however, quantitative arguments are insignificant to the artistic evaluation. It is true that the acoustic aspects of music or the light and colors in a painting can be completely described quantitatively by science, but acoustics does not explain the aesthetic value of a piece of music just as theories of color and geometry cannot explain the aesthetic value of a painting.

\section{Content/Form}

In science, content is important and significant. Einstein's theory of relativity will carry the same importance regardless of how it is presented (as long as it is presented correctly). In art, however, what makes an artistic piece valuable is the way the artistic message is conveyed and not the message itself. One can write a poem about the most noble and important issues which might be artistically worthless, while some of the most magnificent pieces of art might use the simplest concepts and ideas.

\section{Objective Truth/Subjective Truth}

Science aims to reveal the "objective" truth about the physical world. This objective truth is imposed on 
anyone who understands scientific methodology. A work of art, on the other hand, conveys the "subjective" truth of the artist in a form that stimulates us both emotionally and intellectually.

\section{Some characteristics of "valuable" art:}

Although, as was mentioned before, artistic value cannot be defined, we still associate some characteristics with "valuable" art. These characteristics will be important in the discussion of mechanical composition:

\section{The balance between the expected and the unexpected}

Probably the most important attribute in a piece of art is the equilibrium between order and disorder, the regular and the irregular, the predictable and the unexpected. A melody that repeats itself monotonously would become boring after a while. At the other extreme, a random mixture of notes would most likely sound annoying. But, if some interesting change is applied to the monotonous melody, this would attract our attention. The change probably activates an internal mechanism which attempts to find out how it is related to the melody and to "make sense" of it in the context of the melody.

According to one explanation, the human mind was trained in the many years of evolution to look for order and regularity in an unpredictable physical world, since that increased the ability to survive. Artistic pleasure is simply an abstraction of this process. When we hear a piece of music, our attention is continuously dedicated to resolving the "irregularities" in the context of what we have heard so far and what we expect to hear. Once we make sense of what we hear, the tension created is resolved into a feeling of pleasure. From this point of view, the value of a piece of art is the way order and changes are convoluted in each other.

\section{Other Characteristics}

Some other characteristics that we associate with valuable art include: the "compactness" of the ideas, their interrelations, the development of ideas, and how the ideas evolve from one to another. It is not the number of melodies in a composition that is important, but rather how the simplest theme is developed, evolves and changes forms. In fact, one might be tempted to provide a quantitative measure with respect to this characteristic: the "density" of artistic information.

Symmetry, order, coherence, unity, harmony, balance, organization, and elegance.

We often use certain attributes to describe art, e.g. symmetry, order, and coherence. The question is if these attributes are a necessary condition for art. We should observe that these attributes cannot exclusively explain artistic value. These attributes have to do with aesthetics. Art is more than aesthetics however, since it has to convey some "message".

\section{Bach's Music and Mathematics}

If one had to choose a single composer whose music is associated with mathematics, it would be J.S. Bach. Some of his keyboard works - the preludes and fugues, the partitas, the English and French suites - give a strong impression of order and regularity in the way the musical themes are treated and developed (still they are far from being monotonous and dull). The fugue, for example, is a form in which the same musical theme is repeated at different points, up to three or four layers deep. A listener with a mathematical background would be tempted to come up with a mathematical structure describing it. Along these lines, Joseph Schillinger published "The Mathematical Basis of the Arts" [1], which attempted to provide a formal description of the underlying mechanisms in artistic creation and even translate these to the "technology of art production".

The first prelude from "The Well Tempered Clavichord" is a good example to illustrate the regularity, unity and order in J.S.Bach's keyboard music(see fig. 1). The piece is completely based on a simple chord that repeats itself in different variations. One might be tempted to apply Fourier analysis (using the pitch as the amplitude), and derive the "spectrum" of this piece. This type of musical structure seems to be an appropriate candidate for mechanical composition due its regular structure compared to more complex musical forms such as the symphony and concerto.

\section{The diatonic scale, tonal music}

Since the beginning of the 17th century, tonal music dominated the western musical world. Tonal music is based on the major and minor scales which have distinct structures.

The Major scale is composed of 7 tones out of the 12 half tones of the full octave. The intervals are given by the pattern: 221222 (the number of half tones between consecutive tones). It can be shown that three of the notes in this scale are harmonically related to each other. Specifically, if the frequency of the first note (called the tonic) in a major scale is represented by 1 , then the frequency of the third note (called the median) is 1.25 and that of the fifth note (called the dominant) is 1.5. Most musical instruments are harmonic: their sound is composed of a fundamental frequency and multiples of this frequency. For example, the piano and violin are harmonic, but not the drums which do not have a distinct pitch. For this reason, a combination of notes from these three will sound harmonic, since there will be an overlap in their upper harmonics. Sounds which are harmonically 
related are called "consonant" while those which are not, are called "dissonant".

Tonal music is based on the triad of the tonic, dominant and median which were described above. If a piece is written in C Major, then the tones C, G, E carry more weight than other tones in the scale. For example, they might appear more frequently or be used more frequently as the ending note in a musical sentence. In this respect, tonal music has a structure that can be used in mechanical composition.

\section{Combining art and computers}

Computers are powerful tools when it comes to the manipulation of huge data bases and they can implement any process that can be presented formally. The question is how to use this power in art. We can use computers to implement characteristics like symmetry, coherence, order and unity but, as was described before, art cannot be explained exclusively by these properties. What we might want to do is to incorporate some random elements into these regular structures in order to emulate the balance between the expected and the unexpected. Keeping in mind that computer programs can generate a huge number of outputs, we might be lucky and a few might be "aesthetically interesting."

\section{Mechanical composition of music}

Music is one of the most abstract forms of art. It is not subject to semantic restrictions of language like literature. It does not use any concrete concepts from human life, and therefore does not have to comply with any "logic" imposed by these concepts. For that reason, it is a good candidate to choose for mechanical creation of art.

Assuming that there is some correlation between the musical "parameters" (e.g. the frequency distribution of the notes, the time duration of the notes, and the transition between notes) and the artistic value of a piece of music, a statistical approach is a method which is used in the mechanical composition of music.

To begin, a large number of pieces of music (of a certain style, composer and scale so that the selection will be homogenous) are used to extract musical parameters in a form of histograms. For example, the first histogram would provide the frequency distribution of the notes (pitches). For each note, another histogram would be constructed which provides the frequency distribution of the time duration associated with this note. A third group of histograms would provide a note transition distribution and so forth(see fig. 2 through fig. 4).

These histograms are then stored in a data base and used by a program to generate music . The program will have some general forms to choose from (which will determine the length of the piece, the scale, etc). A musical sentence generator will use the data base to randomly pick up notes and time durations using a random number generator and the appropriate histograms. The musical sentences will be combined into a complete piece. The music can be made to sound tonal or atonal and can be written in different scales.

Of course, musical knowledge would be required to establish a more complex and interesting structure in the models used by the program. (One might argue that it is the human involvement that will make the difference in the value of the output).

Thus, the general model used by the program provides the "order," while the fact that musical parameters are chosen randomly provides the unexpected element mentioned before.

A musical piece composed using this method would have the same "musical profile", in terms of the distribution of musical parameters, as that of the selection used to construct the histograms. For example, if the data base is based on Bach's preludes, some of the pieces might resemble Bach's preludes. As stated before, unlike a human composer who has to go through the artistic pains each time he composes a piece, the computer can generate hundreds of pieces in a fraction of an hour and, though it may be a matter of taste, a few of the pieces may prove aesthetically appealing.

\section{Poetry and computers}

Poetry is a compact form of art that can tolerate logical and semantic ambiguity when compared to literary prose. Also in poetry, the requirements of "logical relations" and connectivity between ideas are looser, compared to literary prose. For these reasons poetry can be another good candidate for mechanical composition of art.

\section{Grammatical and semantic classification of vocabulary:}

In addition to the artistic element required of a poem, the sentences should, generally, be grammatically correct and make sense semantically.

The first step is to build a data base of vocabulary which is classified grammatically (as nouns, verbs, adjectives, adverbs, etc.), phonetically (in terms of rhyme, stress and number of syllables) and semantically (in terms of features such as animate/inanimate, abstract/tangible, edible/inedible, natural/man-made, etc.)

The data base would also include information about the semantic relations of the words (e.g. the verb 'to eat' can have only an animate noun as its permissible subject and an edible noun as its permissible object). This information can be used to avoid some anomalous sentences as in "The t.v. ate the fish." (Assuming you wish to avoid semantic anomaly in your poetry.) 


\section{Generating sentences using linguistic models}

Next we need a model to generate sentences. There are two linguistics models that can be used [2]:

\section{World Class Framework: uses sentence prototypes.}

Two basic prototypes and sentence samples are provided below:

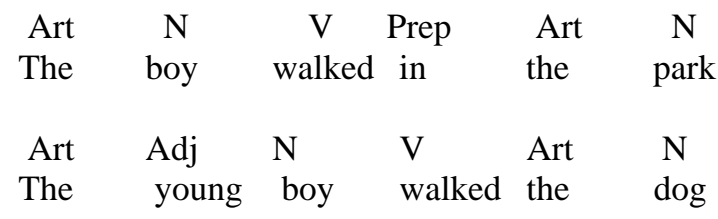

Where:

Art=article, $\quad \mathrm{N}=$ noun, $\quad \mathrm{V}=\mathrm{verb}, \quad$ Prep=preposition, Adj=adjective.

2. Phrase Structure Framework: sentences are generated according to production rules:

Some sample forms of production rules, are provided below:

S-->Noun_phrase Verb_Phrase

Verb_Phrase > Verb (Noun_Phrase) (Prep_Phrase)

Noun_phrase-->(Art) (Adjective) Noun

Prep_Phrase > Prep Noun_Phrase

Where:

-- > indicates a production rule

( ) indicates optional.

Having classified the vocabulary and provided rules for sentence generation, we need to program in some structural parameters, e.g., number of bytes, lines, length, rhyme, and stress. Using a random \# generator, sentences can be generated according to those structural parameters.

The heart of the problem with generating poetry by computer is the coherency of the final output. The sentences may be grammatically correct and may make sense taken individually, but if words are being chosen randomly, the semantic links between sentences are going to be flawed and the whole piece might seem like a collection of unconnected sentences. To improve the semantic links between sentences, one might create "focal points" by having some subjects, nouns or verbs be used at a higher frequency than others, thus providing some "centers of weight" and increasing the "unity" of the piece. Some sentences may be repeated in question form or in slight variation. Here too, the program designer can use his imagination to find ways to increase the "coherency" and unity of the poem.

It is interesting to note that unlike the human writer who has conscious and unconscious inhibitions in selecting words and combing them into sentences, the random selection and combination of words and sentences by the computer program is restricted only by grammatical and semantic rules and therefore one should expect to find some interesting sentences and even hope to find some interesting poems in the large number of outputs that can be generated. Here interpretation may be everything.

\section{Neural Networks and mechanical composition of art}

Neural networks have been found to be useful in systems where the input-output relation cannot be formalized. The problem of defining why we consider one piece of music to be valuable and another to be trivial, cannot be answered in formal and quantitative form. In this context, neural networks can be a useful tool to mimic "good" music. Such a network can be input with various pieces (say of the same composer, or style) so that it will "learn" the hidden properties of that selection and, once its internal structure adapts to the input selection, it can be used to generate music according to the "rules" it has learned.

\section{Bibliography}

1. Schillinger, Joseph: "The Mathematical Basis of the Arts," Philosophical Library, New York. 1948.

2. Baker, C.L.: "Introduction to GenerativeTransformational Syntax," Prentice Hall, New Jersey, 1978, pp. 31-58.

3. AMSCO Music Publishing Co., N.Y., 1937. 


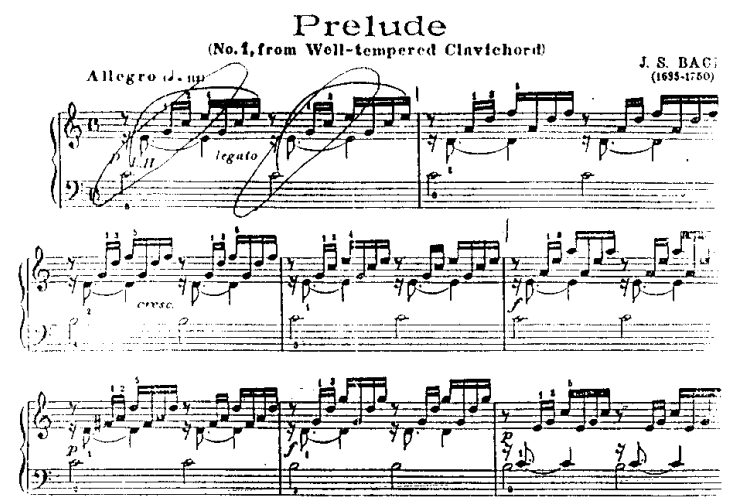

Figure1. Excerpt from Bach's first prelude (from "The Well Tempered Clavichord")

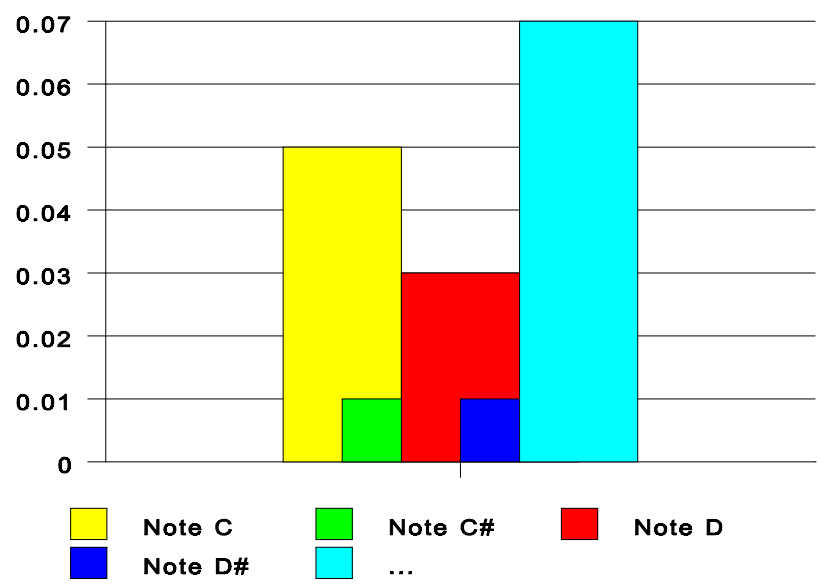

Figure 2. Note distribution histogram
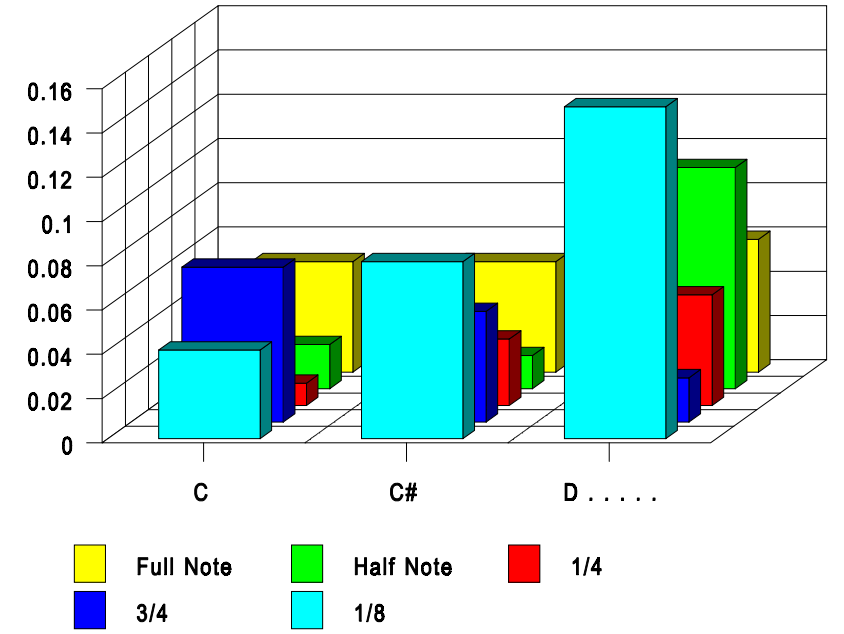

Figure 3. Time duration histograms

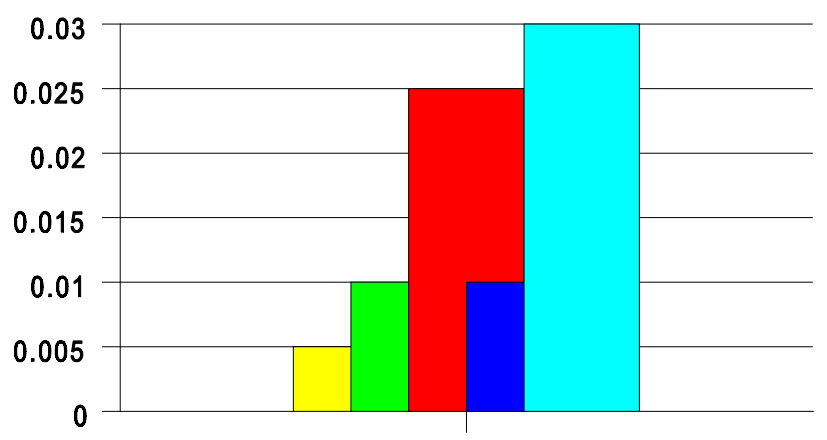

Transition to note $\mathrm{C}$

Transition to note C\#

Transition to note $D$

Transition to note D\#

Figure 4. Note transition histogram for the note $C$ 